\title{
¿Ha muerto la crítica? Una aproximación sociológica a los problemas de legitimación de la crítica periodística
}

\author{
Ibon EGAÑA ETXEBERRIA \\ Universidad del País Vasco (UPV / EHU) \\ ibon.egana@ehu.es
}

Recibido: 5 de diciembre de 2013

Aceptado: 19 de mayo de 2014

\section{Resumen}

El escaso discurso teórico sobre la crítica literaria y artística periodística se ha construido en torno a una retórica de la crisis. Este artículo propone abordar desde una óptica sociológica esta crisis como un problema de legitimación. Por un lado, la estrecha relación de la crítica periodística con la industria cultural la hace vulnerable a las constricciones del mercado. Por otro lado, la crítica es que es una institución prescriptiva, reguladora pero escasamente regulada. A su vez, las nuevas tecnologías y el contexto estético-filosófico parecen poner en entredicho la autoridad del crítico de arte. No obstante, el artículo plantea la necesidad de reformular la vigencia y la función de la crítica, atendiendo a la multiplicación de su sujeto, así como a la reconsideración de la base de su legitimidad.

Palabras clave: profesión intelectual, legitimidad, crítica literaria, industria cultural, internet

\section{Death of the critic?}

\section{A sociological approach to the legitimation problems of reviewing}

\begin{abstract}
The little theoretical discourse on literary and artistic reviewing has been developed upon a rhetoric of the crisis. This paper proposes to address the criticism's crisis as a legitimation problem, from a sociological perspective. On the one hand, the tight relation between reviewing and the cultural industry makes it vulnerable to market's constrictions. On the other hand, criticism is a prescriptive and regulating but scarcely regulated institution. Besides, new technologies and both aesthetic and philosophical discourses seem to question the authority of the art critic. Nonetheless, this paper will put forward the need for reformulation of the function and the validity of criticism, considering the multiplication of the subject of criticism, as well as the reconstitution of its legitimation basis.
\end{abstract}

Keywords: intellectual professions, legitimacy, book reviewing, cultural industry, internet

\section{Referencia normalizada}

EGAÑA ETXEBERRIA, Ibon (2014): “¿Ha muerto la crítica? Una aproximación sociológica a los problemas de legitimación de la crítica periodística”. Estudios sobre el Mensaje Periodístico. Vol. 20, Núm. 2 (julio-diciembre), págs.: 1013-1028. Madrid, Servicio de Publicaciones de la Universidad Complutense.

Sumario: 1. Introducción. 2. De la esfera pública a la industria cultural. 3. El declive de un género periodístico. 4. Una institución reguladora escasamente regulada. 5. Contexto filosófico-estético: preeminencia del gusto, cuestionamiento de la jerarquía de las artes. 6. Los expertos y los consumidores: la crítica en la era Internet. 7. Conclusiones. 8. Referencias bibliográficas.

\section{Introducción}

La legitimidad de la crítica periodística y de los críticos, en especial la legitimidad para emitir juicios de valor y juzgar un libro o cualquier otra producción cultural, ha 
sido puesta en entredicho desde el origen mismo de la crítica literaria moderna' ${ }^{1}$. Los diversos monográficos editados periódicamente por revistas o suplementos culturales y las frecuentes polémicas en torno a la crítica son buena muestra de lo problemático de la legitimidad de la crítica, pues el discurso sobre esta actividad toma la mayoría de las veces forma de "crítica de la crítica" y tiende a denunciar la debacle, las carencias y la incapacidad de la crítica, para dar cuenta de su crisis, incluso profetizando su inminente muerte. Las reflexiones sobre la crítica, tanto a nivel público como en una dimensión más teórica, han desarrollado una retórica de la crisis de la crítica, en especial en lo que concierne a la crítica en los medios de comunicación escritos. La crítica, por tanto, se representa a sí misma en una crisis constante (Roberge, 2011: 441).

Sin embargo, esta retórica de la crisis y del fin de la crítica no está tan lejos de otras retóricas apocalípticas que han augurado el fin de la literatura, del arte e incluso de la historia. Una perspectiva histórica deja en evidencia que esta supuesta crisis no es un fenómeno nuevo, ni es propio de ninguna literatura nacional, sino que es una percepción generalizada en las literaturas occidentales. Es por eso que la crisis y la crítica de la crítica solo cabe entenderla como crisis de legitimidad, debido a las características propias y la posición ambigua de dicha actividad. Es decir, el origen de la crisis de la crítica no es sino su dificultad para legitimarse a sí misma y la labor que desempeña.

\section{De la esfera pública a la industria cultural}

En el contexto de la Teoría Crítica, la teoría habermasiana de la esfera pública desarrolló un marco nuevo para comprender la relación entre la cultura y la política. Si la teoría liberal establecía una clara distinción entre la cultura y la política, la propuesta del joven Habermas supuso una aportación para repensar dichas relaciones (Habermas, 2002). La esfera pública de Habermas es una esfera ubicada entre el estado absolutista y la sociedad burguesa, que ofrece la base para la institucionalización de la crítica literaria moderna, puesto que constituía un espacio para el diálogo sobre la literatura y las artes, así como para el debate político. Como recordó Peter Uwe Hohendahl, la teoría de Habermas tiene una doble función: por una parte, es una herramienta para explicar diacrónicamente el devenir histórico de las relaciones entre la cultura y el estado (y a su vez, la evolución histórica de la crítica literaria, como han mostrado varios trabajos basados en la esfera pública habermasiana; Hohendahl 1982, Eagleton 1999); pero, por otra parte, también es una categoría normativa de crítica política (Hohendahl, 1982: 246). Es decir, también ofrece un modelo teórico-normativo para comprender las relaciones entre la política y la cultura, así como un marco para explicar la base de la legitimidad de la crítica literaria y su progresiva erosión, pues la crítica era una de las principales expresiones de esa esfera².

1 Aunque la reflexión de este artículo parte del ámbito literario, gran parte de la problemática expuesta es común a la crítica periodística sobre otras artes (artes plásticas, escenográficas, visuales, cinematográficas, música etc.)

2 Para un estudio de las relaciones entre los orígenes del periodismo, la crítica literaria y la esfera pública, véase Nitrihual \& Mayorga, 2011. 
La esfera pública burguesa estaba compuesta por personas privadas que razonaban y que cuestionaban así el monopolio que el estado absolutista ostenta sobre la interpretación, según las premisas de la Ilustración ${ }^{3}$. Los temas abordados en estas discusiones estaban, por una parte, relacionados con las artes y la literatura; por otra parte, también eran discusiones sobre la dominación absolutista (Hohendahl, 1982: 247). Dicha esfera pública estaba claramente diferenciada tanto de la esfera privada como del estado. Sin embargo, el desarrollo del capitalismo provoca contradicciones y tensiones dentro de la esfera pública burguesa, pues el mercado, que según la ideología liberal no necesitaba regulación alguna, provoca conflictos económicos y sociales, dando lugar a la intervención del estado y la "estatalización" de la sociedad. Así, la esfera pública comienza a desintegrarse, al perder fuerza la distinción entre la esfera pública y el ámbito privado:

"El intervencionismo viene a ser una traducción política de los conflictos de intereses que no pueden ya seguir desarrollándose en el marco de la esfera privada. De modo que, a largo plazo, coincide también el intervencionismo estatal en la esfera social con la transmisión de competencias públicas a corporaciones privadas [...]. Sólo esa dialéctica de una progresiva estatalización de la sociedad paralela a una socialización del Estado comienza paulatinamente a destruir la base de la publicidad burguesa: la separación entre Estado y sociedad" (Habermas, 2002: 173).

Como consecuencia de la desintegración de la esfera pública, siempre según el modelo ideal de Habermas, la discusión racional sobre temas culturales dejaría lugar al mero consumo cultural; es decir, al pasar de una situación en la que la cultura era ajena al mercado a una sociedad en la que la cultura se convierte en objeto de consumo, los receptores de la cultura dejan de ser individuos privados que discuten racionalmente sobre ella para convertirse en consumidores de una mercancía. A diferencia de la crítica literaria de las revistas del siglo XVIII, en el capitalismo avanzado, el discurso racional sigue teniendo lugar en los medios de masas (en revistas y suplementos de diarios), pero es el mismo medio el que se ha convertido en mercancía, de forma que la crítica no puede ser sino un modo de promoción. La prensa deja de ser un medio público para crear opinión y pasa a ser un objeto comercial que obedece a los intereses de sus anunciantes (Hohendahl, 1982: 244). Por tanto, al desaparecer el medio público que posibilita la mediación entre el arte y su receptor (la esfera pública), la crítica literaria perdería su base institucional, según Habermas. La crítica que ya no puede basar su legitimidad en la esfera pública, busca cobijo en la universidad y en la prensa; en un ámbito, debe renunciar al público amplio; en el otro, debe

3 Como es sabido, la teoría de la esfera pública ha sido objeto de numerosas críticas, desde varios puntos de vista, que denuncian su ilusoria universalidad: desde una perspectiva de género, en cuanto que la supuesta universalidad y libertad del sujeto no concierne sino a los hombres y simplifica en exceso la división entre el espacio público y el privado (Ryan 1992); desde una perspectiva de clase, pues la esfera pública seguía vetada a los miembros de las clases bajas. Además se ha señalado la debilidad de la explicación histórica de la debacle de la esfera, así como el reduccionismo que supone reducir lo cultural a lo económico. (Calhun, 1992; Roberge, 2011). 
ceder a los intereses de la industria cultural. Mattieu Béra ha sintetizado así las consecuencias que la desintegración de la esfera pública acarrea a la crítica literaria (Béra, 2003a: 165).

\begin{tabular}{|l|l|}
\hline Esfera pública & Esfera comercial \\
\hline Interés público & Interés privado \\
\hline Debate racional & Discurso promocional \\
\hline Diversidad de opiniones & Uniformidad del lenguaje \\
\hline $\begin{array}{l}\text { Ética de la discusión, la polémica, la } \\
\text { duda }\end{array}$ & $\begin{array}{l}\text { Ética de la promoción, la afirmación y el } \\
\text { consenso }\end{array}$ \\
\hline Crítica literaria y artística & Consumo \\
\hline Crítica política & $\begin{array}{l}\text { Publicidad, debates gestionados, espec- } \\
\text { táculo, entretenimiento }\end{array}$ \\
\hline
\end{tabular}

La teoría de la esfera pública de Habermas coincide en gran medida con las teorías que sus predecesores de la Escuela de Fráncfort desarrollaron sobre la industria cultural, si bien Habermas, a diferencia de Adorno y Horkheimer, ofrece una explicación histórica del desarrollo de la industria cultural (Hohendhl 1982: 243). A su vez, la teoría de la esfera pública ofrece una perspectiva más optimista sobre la Ilustración que la ofrecida por los teóricos de Frankfurt (Calhoun 1992: 5). El trabajo clásico de Adorno y Horkheimer (1994) acuña el término "industria cultural", con sus connotaciones negativas, para referirse a la producción cultural del capitalismo tardío y para denunciar sus perjuicios:

"El cambio de denominación (industria cultural) muestra, más que nada, la ideología del sistema y las operaciones que, desde éste, se espera que lleve a cabo esa "cultura" (ahora sí, entrecomillada): respecto a los sujetos: disciplinar, guiar, producir deseos, suprimir todo tipo de resistencias". (Zubieta et al., 2000: 119).

Los receptores de la cultura son meros consumidores, por tanto, según estos críticos culturales y las supuestas distintas categorías de arte son sólo productos diferenciados de las empresas culturales; las diferencias entre los productos culturales producidos mecánicamente no tienen ninguna base objetiva. Por ello, rechazan cualquier producción de la industria cultural (el jazz, los dibujos animados...) y también la hipotética democratización de la cultura, a la vez que defienden la cultura de élite, pues hacer el arte más accesible para las masas no conlleva que las masas tengan acceso a ámbitos hasta entonces restringidos, sino que provoca la decadencia de la cultura. Como recuerda Zubieta, la principal diferencia entre Adorno y Horkheimer y Benjamin es el sujeto desde el que parten: en el esquema de Adorno y Horkheimer, el sujeto es el crítico, es decir el crítico del arte de vanguardia, cuya función es rechazar el arte de masas. En el planteamiento de Benjamin, el sujeto de partida es el proletariado de las metrópolis, o sea, el nuevo sujeto histórico del arte de masas.

Por tanto, como consecuencia del desarrollo de la industria cultural, la función de la crítica es puesta en tela de juicio, tanto en la visión de Benjamin, como en la de Adorno y Horkheimer. En la industria cultural, la crítica desaparece, y prevalece el juicio pericial mecánico (Adorno y Horkheimer, 1994 :205). La publicidad adquiere el 
espacio de la crítica, de manera que la industria cultural y la publicidad se diluyen la una en la otra. Adorno, por otra parte, rechaza la democratización de la crítica, puesto que ello supondría la era popularización. Según el filósofo alemán, la antinomia entre la sociedad de masas y la inmanencia estética es difícil de superar y la crítica debería, como en la época romántica, actuar de forma inmanente, sin preocuparse por su recepción (Hohendahl, 1982: 81). En la perspectiva de Benjamin, la época de la crítica forma parte del pasado, pues exige una perspectiva particular y el capitalismo imposibilita dicha diversidad de visiones (Benjamin, 1987).

Con el desarrollo de la industria cultural y con la expansión de la cultura de masas, es la misma literatura la que ha perdido el prestigio, por tanto. En palabras de Hans Magnus Enzensberger el crítico ya no tiene un público al que dirigirse, pues un mercado capaz de absorber la producción cultural más diversa, no puede mostrar sino indiferencia hacia la crítica:

“...el crítico clásico es un militante sin público al cual dirigirse; sus estrategias a largo plazo resultan anacrónicas; su influencia se evapora en la indiferencia de un mercado pluralista al que le importa un bledo la diferencia entre Dante y el Pato Donald. Su autoridad ni siquiera se cuestiona, resulta simplemente superflua". (Enzensberger, 1991: 49).

\section{El declive de un género periodístico}

Por otro lado, en cuanto que la crítica es también un género periodístico, cabe recordar que el campo periodístico tiende a reforzar el polo más comercial del campo artístico o literario (Bourdieu, 1994), de modo que al igual que la industria cultural, el periodismo prioriza las formas periodísticas más comerciales respecto a las que se sitúan en el polo menos comercial. Esa tendencia ha dejado su impronta en la crítica literaria periodística de las últimas décadas, ya que diversas investigaciones en torno a la crítica periodística realizadas en contextos nacionales muy diversos (España, Francia, EEUU o Chile) coinciden en señalar la progresiva disminución del espacio periodístico dedicado a la crítica, un espacio del que se han apropiado otras formas periodísticas, más acordes al polo más comercial del periodismo y a las necesidades de la industria cultural (Gullón, 2004; Kantcheff, 2005; Nitrihual, 2007; Pool, 2007).

La crisis que padece el periodismo en las últimas décadas ha afectado especialmente al periodismo cultural y, por consiguiente, a la crítica literaria. Los problemas financieros de los periódicos, así como la dificultad para obtener nuevos lectores (entre otras cosas, debido al auge de medios digitales y los gratuitos), han provocado una crisis estructural en los periódicos, modificando sustancialmente también los contenidos. Así, las páginas dedicadas a la cultura, la han abordado desde una perspectiva que considera a los lectores como consumidores, abandonando la misma denominación de "Cultura" para la sección y han hecho un hueco en sus páginas a contenidos que transcienden los ámbitos de las artes (Kantcheff, 2005). Estos cambios han afectado indudablemente a la crítica literaria, de manera que puede considerarse un género periodístico en declive (Béra, 2003a: 168). Según el mercado se ha impuesto en el periodismo, las secciones y los géneros periodísticos que son expresión de la subjetividad han perdido espacio, en beneficio de otras formas de periodismo, en las que los consejos de compra y la asesoría de mercado han sustituido en parte al juicio esté- 
tico. Así, el reportaje, el perfil biográfico, las entrevistas, los cuestionarios... Todos estos géneros textuales son formas periodísticos que sirven para esquivar la crítica y la subjetividad.

El periodismo cultural y artístico, por tanto, tiende cada vez más a presentar los temas artísticos como hechos factuales, en lugar de subrayar su dimensión subjetiva y discutible. Todo ello ha influido en la crítica y en los críticos, en distintos aspectos. Por un lado, en lo relativo a las condiciones de trabajo. Los periódicos tratan que los periodistas de la redacción suministren la mayor parte de los textos del diario, aumentando la precariedad de los críticos; las tarifas, a su vez, siguen reduciéndose, de la misma manera que se reduce el tiempo y el espacio que el crítico dispone para la reseña. Por otro lado, la prensa debe, cada vez más, crear "eventos", para que esos mismos eventos sean objetos de consumo (libros-evento, autores-evento, polémicas etc.) y seguir los dictados de un star-system reducido (Kantcheff, 2005). Además, la connivencia de la industria cultural con el periodismo es cada vez más evidente, puesto que sus intereses comerciales coinciden; así, el desarrollo de la industria cultural conlleva el aumento de la publicación de libros, y la obligación de prestar atención a la novedad ha provocado la reducción del tamaño de las críticas; a su vez, la publicación tiende a concentrarse en épocas concretas del año y el periodismo alienta esos acontecimientos, convirtiéndolos en noticias y eventos informativos.

De la misma manera, la dependencia del periodismo respecto a la publicidad dificulta que un periódico pueda obviar una novedad cuya editorial haya contratado publicidad en el medio, incluso en el caso de que no hubiera una presión directa, lo cual pone al crítico en la difícil tesitura de tener que criticar el libro, sin obstaculizar su éxito comercial (Nitrihual, 2007: 143). Por otra parte, diversas investigaciones han señalado que las páginas de los suplementos culturales acogen no solo publicidad de novedades y casas editoriales, sino propaganda de diversos productos, no necesariamente relacionados con la cultura, de forma que estas páginas han pasado de ser un espacio de debate a ser un soporte comercial. Por todo ello, cabe concluir que el periodismo tiende cada vez más a reducir el discurso de corte crítico, pues el punto de vista mercantil establece que los medios son importantes según los recursos financieros que genera.

Enzensberger, así, desde una posición pesimista deudora de la Escuela de Frankfurt, concluía que la crítica periodística como forma y género se halla en un declive imparable:

"Lo realmente grave no es que nuestros recensores sean unos charlatanes y cretinos, sino que la forma de la recensión como tal por lo visto ya no tiene salvación. El periodista literario vive de la sustancia que le ha legado el crítico; cuando ésta se consume, sólo quedan palabras huecas". (Enzensberger, 1991: 52).

\section{Una institución reguladora escasamente regulada}

La crítica literaria es una institución mediadora cuya existencia como tal ha estado en entredicho, entre otras razones, porque, según la aproximación habermasiana, la institución que basaba su legitimidad en la esfera pública, al perder dicha fuente unitaria de legitimación, tuvo que elegir entre dos formas de legitimación: la universidad 
y la academia, por un lado, y la prensa, por otro lado (la cual, como venimos apuntando, está estrechamente ligada al mercado y a la industria cultural). Esa división de la base legitimadora dificulta la visión de la crítica literaria como una sola institución, pues, con la especialización de las profesiones propia de la Modernidad, la base institucional común de las dos formas de crítica no es tan evidente. Por tanto, la crítica es una institución menos compacta y unitaria que otras instituciones culturales, pero no deja de ser, sin embargo, una institución, al ser una actividad que desarrolla su propio campo, dentro de unas limitaciones y según unas leyes propias, aunque frecuentemente el cuestionamiento de esas reglas es más visible que las mismas normas (Roberge, 2011: 440).

La crítica es, pues, una institución reguladora, que posee una función legitimadora dentro del campo literario, creando, otorgando o negando valor literario. Su función no es meramente informativa o interpretativa; su objetivo es convertir sus criterios estéticos en normas del campo literario. Según el análisis de Béra (2003b), para que una institución reguladora sea legítima, es necesario que a su vez la institución esté regulada, y es ahí donde reside una de las claves de la falta de legitimidad de la crítica: la crítica literaria o artística es una institución con función reguladora, pero no regulada. Desde esta perspectiva, la crisis de la crítica sería una crisis de su legitimidad, tanto por la debilidad de sus normas internas (normas profesionales y deontológicas), como por la ausencia parcial o total de normas externas. Este problema de legitimación, no obstante, no es exclusivo de la crítica literaria, ya que las críticas a la autoridad de los periodistas y al periodismo, en general, han sido frecuentes en los últimos dos siglos.

La especialización ha sido, desde finales del siglo XIX, el principio fundamental de legitimación del poder simbólico, en contraste con los siglos XVIII y primera mitad del XIX, donde el habitus de las élites cultivadas en una cultura literaria humanista era la base de ese poder simbólico. En paralelo a la tendencia a la especialización, se produjo una profesionalización de las ocupaciones, incluidas las profesiones intelectuales. Según Gisèle Sapiro, la profesionalización de una disciplina supone asumir las siguientes funciones: regular la formación, controlar el acceso y las condiciones para desarrollar una profesión, formular un código deontológico y códigos de disciplina interna, la ayuda mutua, defender los intereses de la profesión así como su representación (Sapiro, 2006: 10). En lo que respecta a las profesiones intelectuales, cuya principal característica es el elevado nivel de abstracción requerido, la responsabilidad de la formación recae en la universidad o en escuelas especializadas. No obstante, existen profesiones intelectuales que no requieren una formación regulada: la de los escritores y los críticos, por ejemplo. Existen estudios superiores para artistas plásticos; no hay, sin embargo, escuelas de críticos, y eso provoca una constante interrogación sobre la cualificación de los críticos:

"Pourtant, la question de la compétence, et donc de la qualification, fut posée dès l'origine de la critique d'art publique au XVIIIe siècle: d'où parlaient ceux qui s'autoriaient à porter des jugements sur les productions artistiques? Qui ètaient-ils pour s'autoriser à émetre des jugements publics sur un art complexe?". (Béra 2003b: 88) 
Como recuerda Ródenas, "El problema es que no hay centros donde aprender dicha disciplina [...] Y si no las hay es por falta de respeto a la crítica" (Ródenas, 2003: 25). Cuando la crítica literaria moderna se hizo un lugar dentro de la universidad, la crítica académica encontró formas de institucionalización y cualificación, gracias a las titulaciones universitarias; no ocurre lo mismo, sin embargo, con la crítica pública y periodística. Es por eso que cuando se aborda la cuestión de la crítica, ya desde Kant o Hume, gran parte de ese discurso se dedica a enumerar las cualidades que debería tener un buen crítico. No obstante, esas enumeraciones no son más que perfiles de un crítico ideal realizadas desde una visión subjetiva o apelaciones a la ética del crítico, más que descripciones de cualificaciones objetivables ${ }^{4}$.

En lo que respecta a las demás funciones que debe cumplir una profesión intelectual para que sea considerada como tal (regular el acceso, la deontología, etc.), son varias las instancias existentes que tratan de cumplirlas (cámaras, colegios, sociedades, asociaciones, sindicatos). Las condiciones de acceso son más restringidas y controladas en algunas profesiones que en otras. Para que dicho acceso esté controlado, alguna instancia representativa de la profesión debe lograr el monopolio del Estado para otorgar títulos así como para establecer la disciplina interna de la profesión (en el caso de las cámaras de comercio, por ejemplo). Por otro lado, las asociaciones y los sindicatos suelen ser quienes defienden los intereses de la profesión y suministran medios para la ayuda mutua. En ausencia de instituciones con monopolio para regular el acceso, los sindicatos y las asociaciones se encargan de que la profesión tenga alguna forma de regulación y de definir una ética profesional. Aunque dicha ética profesional no posea valor legal, puede, en la práctica, configurar un conjunto de representaciones y esa representación colectiva puede tener consecuencias en la práctica (Sapiro, 2006: 11).

Además de la cualificación, la organización profesional es también débil en el ámbito de la crítica periodística. Si bien en algunos países las asociaciones y los sindicatos de críticos cumplen la función de ayuda mutua y de dignificar la profesión, la profesionalización está lejos de la de otras profesiones intelectuales. El periodismo, por ejemplo, cuenta con una definición de su actividad, lo que permite definir a los periodistas en oposición a los "amateurs". Sin embargo, la mayoría de los críticos desempeñan su labor sin ninguna acreditación profesional; incluso en el caso de quienes trabajan con la acreditación de periodista o la otorgada por alguna asociación, la regulación no deja de ser muy débil. Recuperando conceptos de Durkheim, Béra afirma que la moral profesional se desarrolla cuando los grupos profesionales ganan en consistencia y organización; al contrario, cuando la actividad depende del individuo, dicha actividad puede llegar a ser caótica, fuente constante de conflictos. Por eso sería importante la regulación y la socialización de la actividad, según Durkheim; nada de ello ocurre en la crítica periodística:

${ }^{4}$ Gran parte de la bibliografía acerca de la crítica como género periodístico tiene carácter prescriptvo e identifica las cualidades necesarias para ser crítico y las normas discursivas y éticas a seguir a la hora de redactar una crítica. Véase Armañanzas \& Díaz Noci, 1996, Pool 2007, Vallejo Mejía, 1993. 
“La «morale professionnelle» des critiques est très indigente au plan collectif et ne relève que de règles individuelles ou d'éthiques personnelles. Elle est affaire d'arrangements locaux et en relève nullement d'une régulation collective qui leur permettrait (sas doute) de sortir de cet état de crise continue qui caractérise cette activité et finalement la contraint" (Béra 2003b: 92).

De acuerdo con Boltanski y Thevenot, Roberge propone que la crítica, como institución, posee una ética inmanente y que la ética de los críticos tiene que ver con la ética individual de la vida cotidiana. Es decir, según Boltanski y Thevenot, los individuos apelan a un sentido común de la justicia para guiarse en su vida cotidiana, así como para resolver conflictos o desavenencias. En el caso de la crítica, la exigencia ética es mayor para con el crítico:

"In the case of cultural criticism [...], the pressure to do justice to this or that artifact is doubled by a demand for fairness directed toward the critic himself as a person. He should be sincere, careful, and courageous; his texts or public interventions should have both authenticity and integrity" (Roberge 2011: 441).

Sin embargo, aunque esas exigencias éticas son aceptadas entre los agentes del campo literario, el contenido exacto de la ética "correcta" que el crítico debe tener es indeterminado y fuente de conflictos constantes, pues, en palabras de Roberge, el ethos de la crítica es una caja vacía, debido a la ausencia de regulación colectiva.

Por otro lado, la crítica literaria es una institución carente de regulación externa; es decir, no hay leyes que regulen la crítica. El crítico desconoce dónde están los límites de su actividad; los receptores y creadores tampoco tienen la oportunidad de limitar la actividad crítica o de responder, lo cual erosiona la legitimidad de la crítica:

"L'absence de sanction est un point essentiel qui donne à la critique son parfum d'illégitimité. Il n'existe aucun texte, déontologique ou non, qui organise des sanctions contre des critiques [...] Cette absence de sanction, cette impunité [...] concerne le journaliste et par extension les critiques" (Béra 2003b: 96).

No obstante, la falta de regulación profesional no significa que la crítica carezca de normas prácticas, como consecuencia de actividades repetidas. Sin embargo, la crítica debe reinventar las normas cada vez, pues se basa en leyes implícitas difíciles de explicitar. En ausencia de una regulación colectiva, cada agente se regula según unas normas implícitas adecuadas a su contexto y eso lleva al crítico a tener que reinventarse constantemente, y a una situación de debilidad (Béra, 2003b: 95).

\section{Contexto filosófico-estético: preeminencia del gusto, cuestionamiento de la je- rarquía de las artes}

Los problemas de la crítica periodística a la hora de legitimarse deben ser entendidas, sin embargo, en un marco más general, pues gran parte de la problemática de la crítica se debe al contexto filosófico y estético actual, que tiende a aumentar la desconfianza respecto a la autoridad cultural. Según la extendida concepción de la teoría estética "subjetivista" o "empirista", la estética y la crítica no deben enseñar el gusto verdadero y correcto, ni debe emitir juicios de autoridad sobre las obras, puesto que 
se considera el juicio de gusto una apreciación puramente subjetiva y personal. En ese contexto, el sujeto crítico no puede explicar racionalmente sus elecciones de gusto, pues la razón solo puede explicar aspectos objetivables. Gennette sería uno de los autores defensores del individualismo y la irracionalidad del gusto. Realizando pequeños guiños a Hume y Kant, pero situándose en las antípodas de la lógica axiológica, defiende la inapelabilidad del juicio estético:

"Aunque todos los presentes se desternillen de risa por mi «mal gusto», estoy en mi perfecto derecho de preferir un vino peleón al de Canarias, o Sully Prudhomme a Baudelaire (Hume dice: Ogilby a Milton), y nadie puede imponerme una verdadera preferencia. Plegarme a la opinión de los entendidos sólo sería una falta de autenticidad que no alteraría mi gusto, sino únicamente la falsa exposición que hiciera de él, o en todo caso me llevaría a emitir una opinión contrita como: «A mí me gusta el vino peleón, qué quiere usted que le diga». El «gusto» por esto o por aquello es un hecho psicológico, tal vez fisiológico, no un hecho sobre el que podamos actuar efectivamente desde fuera por obligación o por razones demostrativas: el juicio estético es «inapelable», o sea, autónomo y soberano" (Genette 2000: 76).

Así, considerar el gusto como categoría psicológica más allá de la autoridad cultural, vuelve a cuestionar la legitimidad de la crítica, puesto que iguala el gusto de cualquier receptor y, ya que la justificación de la respuesta psicológico-fisiológica que sería el gusto es difícil, el debate crítico se torna imposible. Es imposible contrastar argumentos sobre la valoración de una obra si no hay argumentos, por lo que el debate crítico deviene absurdo (Kantcheff, 2005: web).

Al convertirse el gusto y la respuesta individual el principal criterio de valoración, es la autoridad cultural (y dentro de ella, la crítica) la que se pone en entredicho. Según Linda Hucheon, en la actualidad el énfasis recae en la "experiencia" (en la experiencia única e intransferible vivida por cada uno al consumir una producción cultural), y cuando esa experiencia se convierte en autoridad, su juicio tiene el mismo valor que el del experto cultural o el profesional (Hutcheon, 2009: 7). Todo ello obstaculizaría, según Kantcheff, y recuperando la idea de la esfera pública habermasiana, el debate crítico racional:

“...le débat critique crée un espace public, fondée sur une rationalité, autour des oeuvres. Un espace public qui s'oppose à l'autorité du message promotionnel, à la puissance du marché et à la loi du grand nombre, que la théorie subjectiviste, au mon de la victoire de la démocratie du goût, qu'elle apparente à celle de la démocratie libérale, favorise" (Kantcheff, 2005: web)

A su vez, según algunos autores, esta "democratización” del gusto (que se podría resumir en el lema "todos somos críticos"), puede llevar a un conservadurismo estético (McDonald, 2007: 12), ya que, según estos autores, los movimientos estéticos rompedores como el modernismo, requerían de un corpus crítico fuerte para poder establecer sus normas estéticas. En resumen, según esta perspectiva, la tendencia subjetivista que cuestiona la legitimidad de la crítica, reduciría las opciones de lectura.

Por supuesto, la desconfianza respecto a la autoridad cultural es una de las características epistemológicas de la cultura postmoderna. Según Lyotard (1984), el vínculo 
social de carácter lingüístico no puede ser único, sino compuesto por diversos juegos de lenguaje. La sociedad estaría atomizada en redes flexibles de juegos lingüísticos, y su poder estaría dispersado en "nubes compuestas por elementos de narratividad", ya que las principales narrativas que establecieron la base de la Modernidad han entrado en crisis, y con ello, también la autoridad cultural que impondría un único significado. La crítica y las artes son también cada vez más descentralizadas, entre otras razones, por el protagonismo que han adquirido las políticas basadas en la identidad y las comunidades diferenciadas.

Según recoge David Harvey, en la postmodernidad la autoridad cultural de los creadores ha entrado en crisis, pues no posee ya autoridad para establecer un único y cerrado significado sobre la obra, y deja en manos del consumidor la opción de estructurar significados y unir fragmentos de significado. No obstante, esa pérdida de la autoridad, al tiempo que abre la oportunidad a una recepción más activa y participativa, también conlleva el riesgo de que los criterios mercantiles se impongan:

"Tanto los productores como los consumidores de «textos» (artefactos culturales) participan en la producción de significaciones de sentidos (de allí el énfasis que otorga Hassan al «proceso», a la «performance», al «happening» y a la «participación» en el estilo posmodernista). Al minimizarse la autoridad del productor cultural, se crean oportunidades de participación popular y de maneras democráticas de definir los valores culturales, pero al precio de una cierta incoherencia o -lo que es más problemático- vulnerabilidad a la manipulación por parte del mercado masivo" (Harvey 2008: 68).

McDonald coincide con Harvey en esa opinión y añade que considerar el gusto individual como único criterio válido, negando la autoridad de los críticos, es la perspectiva que mejor se adapta a los intereses de una sociedad de mercado, pues se allana el camino a los monopolios, la industria cultural y a la gratificación inmediata (McDonald 2007: 17).

Junto con la autoridad cultural, las jerarquías culturales también han sido cuestionadas en algunas variantes del pensamiento postmoderno. Así, según propone Frederic Jameson partiendo de la arquitectura contemporánea, (Jameson, 1991) en el capitalismo avanzado la división entre la alta cultura y la baja cultura tiende a difuminarse, pues las producciones estéticas se convierten en bienes de mercado y la producción cultural se limita a satisfacer las necesidades de novedad del mercado, de manera que se ha reorganizado el espacio que ocupaban las artes en la sociedad. A su vez, los estudios culturales han contribuido a consagrar, al tomar como objeto de estudio en el contexto de la crítica universitaria, obras de la baja cultura y la cultura de masas. En este contexto, pues, la división entre el arte legítimo y el no-legítimo, pierde vigencia y, por lo tanto, también la actividad discursiva que se encargaría de establecer la distinción entre los dos tipos de arte (es decir, la crítica). La difuminación entre las diferentes jerarquías artísticas, por tanto, hace inevitable repensar la función de la crítica.

De la misma manera, la homología y la correspondencia expuesta por Bourdieu en su conocido trabajo La distinción (1979) entre el consumo de la cultura alta y la cultura baja y el estatus social de los consumidores se ha ido transformando en las últi- 
mas décadas, a la luz de algunas investigaciones recientes (Verboord, 2010; Van Eijck y Knulst, 2005). Por un lado, por que el consumo de las artes consideradas elevadas (la música clásica, el teatro o la literatura culta) ha ido en descenso en todas las clases sociales y, por otro lado, por que la posición social dominante no es homóloga a los gustos elevados, ya quelas clases altas combinan el consumo de gustos culturales de diverso estatus. Según la hipótesis de Peterson y Kern (1996), el esnobismo ha sido sustituido por un "omnivoridad" cultural en las últimas décadas. Coincidiendo con las hipótesis de DiMaggio (1987), afirman que los miembros de las clases altas consumen no solo cultura alta, sino también géneros considerados de la cultura baja. De todas formas, esa clase alta culturalmente "omnívora" no consume cualquier producción cultural indiscriminadamente:

"As we understand the meaning of omnivorous taste, it does not signify that the omnivore likes everything indiscriminately. Rather, it signifies an openness to appreciating everything. In this sens it is antithetical to snobbishness, which is based fundamentally on rigid rules of exclusion [...] such as: «It is de rigueur to like opera, and country music is an anathema to be shunned»" (Peterson \& Kern, 1996: 904)

Con el desarrollo de los "omnívoros" culturales, la transformación de la homología entre las clases sociales y la jerarquía de los gustos, la autoridad cultural y la legitimidad de los agentes que otorgan valor simbólico (la de los críticos, entre otros) se pone en cuestión, pues el repertorio ecléctico del gusto "omnívoro" difícilmente puede reducirse al sistema tradicional de reconocimiento de valor y a la separación jerárquica entre géneros establecida institucionalmente por los críticos (Verboord, 2010: 626). No obstante, tal y como observan Peterson y Kern, la "omnivoridad" cultural no conlleva el fin de la necesidad de distinción; al contrario, no acarrearía sino una remodelación de las formas y fronteras de la distinción. Por un lado, porque dentro de cada género existe una distinción de gustos (elevado/bajo), y porque no todas las producciones de una misma disciplina artística poseen la misma legitimidad (comparemos Radiohead con Britney Spearce, dentro de la música pop). Por otro lado, aunque esté abierto a producciones culturales de varios tipos, el "omnívoro" cultural tenderá a mostrar conocimientos sobre esos géneros, así como a criticarlos, adquiriendo la base intelectual necesaria para ello en revistas especializadas, por ejemplo (en revistas de jazz o de música pop). Así, la "apertura" del omnívoro es limitada y cualificada, puesto que la "omnivoridad" no es sino otra forma de mostrar y negociar la distinción y, por tanto, la legitimación y el conocimiento otorgado por la crítica sigue siendo útil para él, aun partiendo desde otra base.

\section{Los expertos y los consumidores: la crítica en la era Internet}

El desarrollo de Internet y de la web 2.0 ha supuesto un cambio, también en la forma de entender la crítica y, sobre todo, en lo que respecta a la legitimidad de los críticos, pues no se puede obviar que algunas estructuras culturales fundamentales en la era del libro impreso para la legitimación de la crítica están sufriendo un cambio profundo, y ello hace necesario repensar la legitimidad de la crítica periodística y de los críticos. Entre otras cuestiones, en la era de Internet, las jerarquías de valoración cultural no pa- 
recen tan estancas como antaño; por otra parte, han proliferado los críticos y los espacios para la crítica; la distinción entre los géneros de la cultura alta y la baja no parece tan fijada como antes, y la separación institucional entre los profesionales y los aspirantes de un campo cultural no es tan nítida (Verboord, 2010: 625). Esto no supone, claro está, que las jerarquías culturales hayan desaparecido, o que no haya distinciones entre críticos profesionales y amateurs, pero en la medida en que Internet ha transformado esos esquemas, es necesario repensarlos.

A la hora de abordar los cambios que ha provocado Internet en el ámbito cultural, se han desarrollado dos narrativas principales: un discurso de orientación optimista y otro de corte pesimista. Según el discurso optimista, Internet no es sólo una tecnología, sino una herramienta que ha provocado cambios culturales de mayor calado, y que ha promovido la libertad, la opción de compartir o el empoderamiento de los usuarios, dando lugar a un nuevo modelo cultural, basado en la libertad y en la economía del intercambio de información. El discurso pesimista respecto a Internet, por otro lado, denuncia la masificación de la cultura y del conocimiento que ha provocado, entendiendo que promueven la ignorancia y el egoismo. Coincidimos con Roberge (2011) en que ante la posición utópica y la distópica, hay un espacio para la aproximación analítica, siendo conscientes de que Internet es origen de conflictos de interpretación y de discursos en varios niveles. Lo expuesto sobre la consideración de la influencia de Internet en el ámbito cultural es válido también para explicar los cambios sufridos por la crítica con la consolidación de Internet.

El desarrollo de Internet y de la crítica on-line ha supuesto un revulsivo para la institución de la crítica. Por un lado, ha provocado un cambio cuantitativo, pues Internet ha incrementado sustancialmente el número de críticas y reseñas disponibles (quizá en relación inversamente proporcional a su presencia en los medios impresos) y casi cualquier manifestación cultural o social se ha convertido en posible objeto de la crítica (producciones culturales antes consideradas no-legítimas, por ejemplo: la gastronomía, el hip hop); pero más allá de eso, es la misma relación crítica la que se ha transformado (Roberge, 2011: 445), pues, gracias a las opciones que abre Internet para la participación, la interacción ha llegado también al ámbito de la crítica, dando a los lectores la opción de contestar al crítico o de mostrar el desacuerdo. Así, la crítica ha cambiado en tanto que institución con el auge de Internet: si antes era una institución mediadora entre la producción artística y el receptor, ahora es un "mediador entre mediadores" (no tan lejos de la imagen del "disc-jockey" expuesta por Reinhart Baumgart, en Hamm, 1971).

Sin embargo, las investigaciones empíricas realizadas en este ámbito han mostrado que Internet no ha eliminado del todo el sistema de evaluación cultural tradicional, ni la legitimidad de los críticos expertos. Según concluye Verboord, en gran medida, es el mismo público que consulta los medios impresos el que consulta las críticas de Internet, a las que consideran complementarias más que sustitutas de las críticas de los medios impresos. Roberge también afirma que, tomando como ejemplo el New York Times, los críticos de los medios legitimados institucionalmente, siguen ostentando poder, pero que han perdido parte del "aura" que poseían en el pasado, como consecuencia de la divulgación de una práctica antes exclusiva. De la misma manera, tanto 
Roberge como Verboord constatan que dentro de la crítica de Internet, están surgiendo jerarquías y clasificaciones de críticos 5 .

\section{Conclusiones}

La crisis de la crítica, como se ha expuesto, se debe, en parte a la posición ambigua y fronteriza en la que se ubica: entre la industria cultural y el campo literario, entre la universidad y la prensa. Se trata de una institución débilmente regulada, por lo que debe afirmar constantemente la legitimidad para realizar su labor y emitir juicios de valor. Además, la vinculación de la crítica pública con la prensa, y de ésta con el mercado y la industria cultural provocan la sospecha constante entorno a la independencia y a la legitimidad de la crítica para enjuiciar.

Por otro lado, la crítica es una institución inequívocamente ligada al paradigma moderno ilustrado, según el cual existiría una estética pura, desinteresada y universal, tal y como lo describe la esfera pública propuesta por Habermas. No obstante, esa hipotética e idealizada esfera en la que tiene lugar la discusión sobre temas estéticos, ajena al mercado y al estado, parece hoy a todas luces imposible, tanto por la estrecha vinculación entre el mercado, la industria cultural y la crítica, así como por la crisis del sujeto moderno y la multiplicidad de voces que denuncian su ilusoria universalidad y libertad. A su vez, la organización y clasificación de las artes en torno a la oposición alta / baja cultura, cuya garante ha sido la crítica, ha dejado paso a una renegociación de las nociones de alta y baja cultura, que se resuelve de forma distinta según contextos nacionales o locales. Asimismo, las nuevas tecnologías que promueven la participación activa del lector, así como la progresiva sublimación del gusto individual como criterio único ponen en cuestión la autoridad cultural y la función de la crítica tradicional.

No obstante, estas dificultades por las que atraviesa la crítica (algunas contemporáneas, otras no tanto), no han provocado la desaparición de esta práctica, vaticinada casi desde su surgimiento. Existen, en cambio, indicios que contradicen los augurios de su extinción: la proliferación de críticas y reseñas en Internet y en las redes sociales o el abanico de producciones culturales cada vez más amplio que abarca la crítica muestran que aun cuando se cuestiona la autoridad cultural y la labor de la crítica "profesional", la crítica periodística sigue siendo requerida por una parte de los lectores. Por otro lado, las investigaciones empíricas muestran que las nuevas formas de crítica conviven con las tradicionales formas de autoridad cultural, pues si bien las jerarquías culturales se han difuminado, se están creando nuevas formas de clasificación y jerarquización menos establecidas.

Por todo ello, cabe concluir que la crisis de la legitimidad de la crítica no conlleva su desaparición, sino que plantea la necesidad de reformular su vigencia y su función, así como la reconsideración de la base de su legitimidad.

5 Por ejemplo en el portal rottentomatoes.com, el lector puede escoger entre tres tipos de críticos: "Top critics", "Rotten Tomatoes Community" o "Friends". Es decir, en cierta medida, se están recreando las jerarquías de legitimidad dentro del discurso cultural de Internet, en principio no tan jerarquizado. 


\section{Referencias bibliográficas}

ADORNO, Theodor. \& HORKHEIMER, Max (1994): Dialéctica de la ilustración. Madrid, Trotta.

ARMAÑANZAS, Emi \& DÍAZ NOCI, Javier (1996): Géneros de opinión. Bilbao, UPV /EHU

BENJAMIN, Walter (1987): Dirección única. Madrid, Alfaguara.

BÉRA, Mattieu (2003a): "La critique d'art, une instance de régulation non régulée". Sociologie de l'art, $\mathrm{n}^{\circ}$ 3, pp. 79-100.

BÉRA, Mattieu (2003b): “Critique d'art ou promotion culturelle?". Réseaux, n 117, pp. 153-187.

BOURDIEU, Pierre (1991): La distinción. Criterio y bases sociales del gusto. Barcelona, Taurus.

BOURDIEU, Pierre (1994): "L'emprise du journalisme". Actes de la recherche en sciences sociales, $\mathrm{n}^{\circ}$ 101-102, pp. 3-9.

CALHOUN, Craig (ed. 1992): Habermas and the public sphere. Cambridge MA, MIT Press.

DIMAGGIO, Paul (1987): “Classification in Art". American Sociological Review, $\mathrm{n}^{\circ}$ 52, pp. 440-455.

EAGLETON, Terry (1999): La función de la crítica. Barcelona, Paidós.

ENZENSBERGER, Hans Magnus (1991): Mediocridad y delirio. Barcelona, Anagrama.

GENETTE, Gérard (2000): La obra del arte. La relación estética. Barcelona, Lumen.

GULLÓN, Román (2004): Los mercaderes en el templo de la literatura. Madrid, Caballo de Troya.

HABERMAS, Jürgen (2002): Historia y crítica de la opinión pública: la transformación estructural de la vida pública. Barcelona, Gustavo Gilli.

HAMM, Peter (ed., 1971): Crítica de la crítica. Barcelona, Barral.

HARVEY, David (2008): La condición de la posmodernidad. Investigación sobre los orígenes del cambio cultural. Buenos Aires, Amorrortu.

HOHENDAHL, Peter Uwe (1987): The institution of criticism. New York, Cornell University Press.

HUTCHEON, Linda (2009): "Reviewing reviewing. No customer reviews yet. Be the first (amazon.com)". Literary Review of Canada, vol. 17, nº 6, pp. 6-8.

JAMESON, Fredric (1991): El posmodernismo. O la lógica cultural del capitalismo avanzado. Madrid, Paidós.

KANTCHEFF, Christophe (2005): "La critique sous contraintes". Institut Français de Presse. En: http://ifp.u-paris2.fr/68594366/0/fiche article/\&RH=IFP-JSEMINAIRE. [fecha de consulta: 1 de diciembre de 2013] 
MCDONALD, Ronan (2007): The death of the critic. London, Continuum.

NITRIHUAL VALDEBENITO, Luis (2007): "La crítica literaria de la revista de libros del diario chileno El Mercurio, entre los años 2002-2004. Acerca de la importancia de la publicidad en los medios de prensa". Palabra-Clave, vol. 10, $\mathrm{n}^{\mathrm{o}} 2$, pp. 135-145.

NITRIHUAL VALDEBENITO, Luis A. y MAYORGA ROGEL, Alberto Javier (2011): "La crítica literaria en los orígenes del periodismo". Estudios sobre el mensaje periodístico, vol. 17, $\mathrm{n}^{\mathrm{o}} 1$ (enero-junio), pp. 183-194. Madrid, Servicio de Publicaciones de la Universidad Complutense.

PETERSON, Richard \& KERN, Roger (1996): "Changing highbrow taste: from snob to omnivore". American Sociological Review, vol. 61, n 5, pp. 900-907.

POOL, Gail (2007): Faint Praise. The plight of book reviewing in America. Columbia, University of Missouri Press.

ROBERGE, Jonathan (2011): "The aesthetic public sphere and the transformation of criticism". Social Semiotics, vol. 21, nº 3, pp. 435-453.

RÓDENAS DE MOYA, Domingo (2003): "La crítica literaria en la prensa del siglo XX”, en RÓDENAS, D. (ed.): La crítica literaria en la prensa. Madrid, Marenostrum, pp. 183-213.

RYAN, Mary P. (1992): “Gender and public access: women's politics in nineteenthcentury America". In CALHOUN, Craig J. (ed.): Habermas and the Public Sphere, pp. 259-288.

SAPIRO, Gisèle (2006): "Les professions intellectuelles entre l'état, l'entrepreneuriat et l'industrie". Le Mouvement Social, vol. 214, pp. 3-18.

VALLEJO MEJÍA, Mary Luz (1993): La crítica literaria como género periodístico. Pamplona, Universidad de Navarra.

VERBOORD, Marc (2010): "The legitimacy of book critics in the age of the Internet and omnivorousness: Expert critics, Internet critics and peer critics in Flanders and the Netherlands". European Sociological Review, vol. 26, nº 6, pp. 623-637.

ZUBIETA, María, et al (2000): Cultura popular y cultura de masas: conceptos, recorridos y polémicas. Buenos Aires, Paidós. 